\title{
Gestão participativa e sustentabilidade socioambiental: um estudo em escolas da rede pública de Sobral-CE
}

\author{
Participative management and social-environmental \\ sustainability: a study in public schools of Sobral-CE
}

Renato de Oliveira Brito ${ }^{1}$. Célio da Cunha ${ }^{1}$. Luiz Siveres ${ }^{1}$

\begin{abstract}
Resumo: Este estudo analisa os indicadores de influência da gestão participativa no desenvolvimento de projetos escolares, contemplados pelo Programa Dinheiro Direto na Escola (PDDE) - Escolas Sustentáveis, que visaram a promoção de uma educação socioambiental. Os dados foram gerados mediante entrevistas semiestruturadas realizadas com diretores, professores, coordenadores e alunos em quatro escolas contempladas pelo programa. A partir de um universo de 15 participantes, os resultados confirmaram a premissa de que a gestão participativa, acrescida do apoio financeiro institucional aos projetos da escola, enriqueceu tanto o ambiente escolar como o ambiente social no que concerne à questão da conservação e da preservação do meio ambiente, com objetivo de possibilitar uma qualidade de vida melhor para a geração presente e futura. Baseou-se a identificação dos sentidos que os participantes atribuem às suas ações e conquistas em ambientes escolares que permitissem ampla participação e diálogo. Assim, culminou a criação do que se chamou aqui de indicadores de sustentabilidade socioambiental em escolas de gestão participativa.
\end{abstract}

Palavras-chave: Recursos financeiros. Gestão participativa. Sustentabilidade socioambiental. Escolas públicas.

\begin{abstract}
This paper analyses the influence indicators of participative management in the development of educational projects that aimed to promote a socio-environmental education, covered by the "Programa dinheiro direto na escola: escolas sustentáveis" ("Money straight in school program: sustainable schools"). The data was generated through semi-structured interviews conducted with principals, teachers, coordinators and students at four schools covered by the program. From a sample of 15 participants, the results confirmed the assumption that the participative management, complemented by the institutional financial support to school projects, enriched both the social and the school community about the environment conservation and preservation issues, to provide a better quality of life for the present and future generations. Schools that allow broad participation and debate enabled the identification of the meanings attached by the participants to their actions and achievements. Thus, the creation of the indicators of the environmental sustainability in schools of participative management was obtained.
\end{abstract}

Keywords: Participative management. Financial resources. Social-environmental sustainability. Public schools.

\footnotetext{
${ }^{1}$ Universidade Católica de Brasília (UCB), Brasília, DF, Brasil. E-mail: <renatoorios@gmail.com>.
} 


\section{Introdução}

Nas últimas décadas, a escola recebeu novas exigências da sociedade em todos os sentidos. Isso tem estimulado os profissionais da educação para novos desafios, entre os quais compreender e exercitar em seu cotidiano os princípios da sustentabilidade. Lamentavelmente, parece que esse tema não tem alcançado, na mesma proporção da sua necessidade, a importância e visibilidade que deveria. As questões socioambientais internalizadas e vividas a partir dos ambientes educacionais são de importância crucial para a qualidade de vida das gerações atuais e, mais ainda, das gerações futuras.

Como não poderia deixar de ser, a escola, como fonte de desenvolvimento humano, social e educacional, deve assumir o seu lugar no engajamento em prol do meio ambiente e considerar enquanto forma de atuação a consolidação da gestão participativa. Além disso, deve partir da escola a iniciativa de incorporar esse papel e o desafio de motivar e orientar o engajamento da comunidade interna e externa, para que todos participem conjuntamente da construção e preservação de princípios que conduzam o desenvolvimento socioambiental (LOUREIRO; AZAZIEL; FRANCA, 2003). Desse modo, a escola buscará promover a educação ambiental por meio de seus próprios projetos, orientados e desenvolvidos em processos de coparticipação. Ao mesmo tempo, também modificará gradativamente sua estrutura de gestão tradicional para outro embasado nos pressupostos da gestão participativa.

Sabe-se que a necessidade da escola de implementar projetos que desenvolvam a educação ambiental vincula-se ao imperativo de formar cidadãos capazes de interagir em uma sociedade sustentável onde prevaleça a economia verde, ou seja, "aquela que resulta em melhoria do bem-estar da humanidade e em igualdade social, ao mesmo tempo em que se reduzem significativamente riscos ambientais e escassez ecológica” (VELLOSO et al., 2012, p. 15).

Em face da convergência e da pertinência dessas questões para os problemas contemporâneos, buscou-se pensar em mais uma vertente que poderia propiciar a melhoria da qualidade na Educação, com a reintegração do tripé gestão-comunidade-participação. Para tanto, a metodologia adotada no estudo foi desenvolvida no sentido de conhecer como se deu a aplicação dos recursos financeiros oriundos da União, utilizados como meio de propagar princípios da sustentabilidade e promoção da educação ambiental na escola.

Esse foi o tema explorado como questão central da tese de doutorado defendida por Brito (2016), cuja abordagem deu-se em torno de uma questão: a sustentabilidade socioambiental como um desafio educativo no cotidiano de escolas da rede pública de ensino, mais especificamente, da cidade de Sobral, no Estado do Ceará. Concretizaram-se os objetivos da referida tese a partir do estudo de quatro escolas que se destacaram das demais no quesito gestão e aprendizagem. Buscou-se usar como estratégia os dados documentais que caracterizaram os investimentos aplicados em projetos de sustentabilidade socioambiental dessas escolas, além dos dados que corroboraram a escolha dos espaços como os mais indicados, visto que o investimento do Programa Dinheiro Direto na Escola (PDDE)-Escolas Sustentáveis gerou resultados bastante positivos. Decidiu-se também diversificar os segmentos dos participantes, de modo que diferentes níveis de atuação fossem envolvidos. Assim, a abrangência estendeu-se aos membros do corpo gestor, coordenadores, professores e alunos. 


\section{Escola: agente de uma educação ambiental transformadora}

A respeito da visão de escolas sustentáveis adotada neste artigo, observou-se a visão que recomenda o Ministério da Educação em sua Resolução CD/FNDE n ${ }^{\circ}$ 18, de 21 de maio de 2013 (BRASIL, 2013). Conforme a Resolução, existe uma relação bastante próxima entre a escola e o meio ambiente e, a força da materialização dos princípios que emergem a partir dessa relação é o que propicia um equilíbrio frente ao impacto exercido pelo desenvolvimento de tecnologias. A gestão está inserida e citada como uma das importantes dimensões nesse processo de transição para a sustentabilidade.

Por sociedade sustentável entende-se uma estratégia de desenvolvimento executada de modo coletivo e que produz o crescimento econômico necessário, o que garantiria a preservação do meio ambiente e o desenvolvimento social para o presente e para as gerações futuras. A educação, por sua vez, como pioneira na transmissão e formação de opiniões, pode ser aliada para que se realizem projetos e ações que atendam ao princípio da responsabilidade que o ser humano tem para com as futuras gerações. Usar os recursos naturais de forma consciente pode representar uma nova forma de desenvolvimento econômico que levaria em conta o respeito ao meio ambiente. Para tanto, o desenvolvimento sustentável exige a implementação de inovações nos sistemas e processos educativos e de ensino-aprendizagem (ESCOLANO BENITO; HERRERO SUÁREZ; BRYAN, 2011).

À luz de Beraldo e Pelozo (2007), partiu-se do pressuposto que uma visão comum, incorporada, disseminada e compartilhada entre as pessoas que compõem a comunidade escolar pode contribuir na construção de objetivos, metas, caminhos teóricos e práticos a serem seguidos na construção do Plano de Desenvolvimento da Escola, documento que dá o suporte e o direcionamento sistemático para os seus projetos financeiros e pedagógicos. Também é importante considerar que, por se tratar de um espaço público, a escola deve apresentar-se como um ambiente aberto e comum a todos, com a oferta de plena abertura para a participação de seus usuários, governando e deixando-se governar por todos, de forma responsável e partilhada.

Nesse sentido, há de se concordar que caberá sempre à escola o papel de agente de uma educação ambiental transformadora, na medida em que ela traz para si o espectro de uma responsabilidade precípua na formação de cidadãos conscientes dos reflexos no futuro de suas ações no presente. A sustentabilidade socioambiental, trabalhada no contexto da gestão participativa, mostrou-se um potente favorecedor do desenvolvimento dessa consciência.

\section{A gestão participativa no contexto da sustentabilidade ambiental}

Brevemente, apresentam-se alguns aspectos conceituais que trazem luz à relação entre gestão participativa e sustentabilidade ambiental. A participação de todos os cidadãos em prol da sustentabilidade do meio ambiente é um processo apto ao sucesso. Quando o ser humano começa a se desenvolver de forma multifacetada e em comunidade, emergem ideias e formas de executar ações que provavelmente não teriam sido pensadas em termos individuais. Do mesmo modo, ações sustentáveis são sempre inovadoras e podem surgir de todas as faixas etárias, classes sociais e níveis de escolaridade. Nessa percepção, faz-se oportuno trazer aqui a ideia de ecomunitarismo, que, segundo a compreensão de Velasco (2015, p. 156), constitui 
[...] a ordem socioambiental pós-capitalista na qual os seres humanos reconciliam-se entre si para permitir e incentivar solidariamente o desenvolvimento pleno de cada sujeito, e se reconciliam com o restante da natureza, mantendo em face dela uma atitude permanente de preservação e regeneração.

Pode-se compreender o ecomunitarismo como uma forma de ação comunitária, voltada para o desenvolvimento de atitudes e valores que visem a preservação do meio ambiente e a realização de ações práticas para a sustentabilidade. Logo, o processo de transição para uma sociedade mais sustentável depreende da estruturação de uma visão interdisciplinar e integradora do conhecimento e da educação, o que só poderia ocorrer através de uma prática holística de interação e integração de todos os agentes envolvidos no processo educacional (ESCOLANO BENITO; HERRERO SUÁREZ; BRYAN, 2011). Isso porque, segundo Brito (2013), em todas as perspectivas de união da escola com a comunidade, pressupõe-se liderança e empoderamento como elementos-chave para o processo.

Liderança e empoderamento são capacidades passíveis de serem aprendidas, conquistadas e concretizadas no âmbito da gestão escolar. Porém, requerem um processo profundo de reflexão e de orientação adequada para o exercício da autonomia, do protagonismo na tomada de decisão e da ação responsável. Uma liderança que atue com esses princípios tende a corresponder às aspirações mais legítimas da comunidade escolar e à vivência da sua cidadania de forma ativa. Assim, a sustentabilidade, internalizada de modo profundo na mentalidade dos agentes envolvidos, pode se tornar uma espécie de ferramenta para que essa aproximação se torne real. Pela própria natureza do conceito e da visão a que reporta, ser sustentável implica pensar na direção do outro e do ambiente, na perspectiva da perpetuidade, conceito que contrasta com a superficialidade.

Esse poderia ser o foco das instituições de ensino, às quais não deveriam enfatizar somente a questão de rendimento dos alunos, mas também no seu desenvolvimento integral, na sua capacidade de conviver de forma ética e harmoniosa em sociedade e em sua competência de tomada de decisão sustentável ao longo da vida. A questão crucial é que a liderança pode contribuir para mudanças na forma com que os alunos, pais e comunidade percebem $o$ valor de uma educação suficientemente boa em suas vidas. A partir dessa percepção, torna-se tangível para o líder atuar positivamente no envolvimento das partes nessa nova perspectiva de convivência. Em suma, para que haja desenvolvimento sustentável, a participação é um pressuposto primordial.

\section{Metodologia do estudo realizado}

Este artigo faz referência a uma tese de doutorado de Brito (2016), que investigou no cotidiano de quatro escolas o impacto da gestão participativa nas ações voltadas para a sustentabilidade socioambiental. Teve como diferencial a análise do contexto da participação da União, a partir do investimento financeiro nos projetos idealizados pela comunidade escolar e as possibilidades que emergiram a partir da gestão conjunta desses recursos.

As ações socioambientais promovidas pelas escolas envolveram a conscientização e o combate à dengue, a coleta de materiais recicláveis, a troca das lâmpadas das salas de aula 
por modelos mais econômicos, o uso hídrico racional pela captação da água utilizada nos arescondicionados e bebedouros. Nesse último caso, a água coletada foi utilizada para a irrigação de uma horta comunitária, onde as hortaliças e as leguminosas produzidas eram utilizadas na própria merenda escolar, de modo que a ação impactou o próprio hábito alimentar dos alunos, além da questão ambiental em si. Os projetos promovidos impactaram também as famílias, que passaram a se aproximar de outras atividades promovidas pelas escolas.

Quanto ao tipo de abordagem, a investigação foi fundamentada na pesquisa qualitativa, com ênfase na natureza descritivo-analítica. A entrevista semiestruturada foi utilizada como instrumental técnico e possibilitou incorporar os significados e as intencionalidades presentes nos atos, relações e estruturas sociais da comunidade investigada, valorizadas pelo pesquisador como construções humanas significativas (BARDIN, 2011). A análise qualitativa caracterizou-se, pois, como apropriada para a realização do estudo da história, das relações, interações e representações sociais, das crenças, das percepções e dos juízos que resultam das interpretações que os seres humanos realizam sobre o próprio modo de viver, os objetos que constroem e como constroem a si próprios, como sentem, idealizam e pensam (TURATO; RICAS; FONTANELLA, 2008).

Além da entrevista semiestruturada, procedimento que permitiu obter os dados primários, realizou-se observações in loco - cujo roteiro foi composto pelas anotações e posterior sistematização das notas de campo - e análise documental. Como notas de campo, considerouse tudo que foi registrado dos episódios espontâneos observados durante o processo de geração de dados. Convencionalmente, existe um conjunto de regras orientadas para um planejamento prévio de observações in loco (LÜDKE; ANDRÉ, 2003), porém, tendo em vista os objetivos do estudo, isso não foi elaborado a priori. Decidiu-se seguir o fluxo natural permitido pelo contexto empírico, com o registro dos eventos emergentes, conforme fosse considerado relevante e pertinente para o alcance dos objetivos.

Quanto à observação in loco foi importante notar como as emergências do contexto auxiliaram na obtenção e identificação de elementos mais concretos, legitimados pela espontaneidade na atuação dos participantes. Isso pode configurar-se como uma forma indireta de validação dos dados. Para Lakatos e Marconi (2002), trata-se daqueles elementos e aspectos dos quais os participantes não têm consciência, entretanto, são o que conduz o comportamento deles naquele ambiente. Concorda-se com esses autores, uma vez que estar por alguns momentos no ambiente da pesquisa desempenhou papel fundamental no estabelecimento de um contato mais direto com a realidade investigada.

Para a análise documental, considerou-se a extensa pesquisa realizada sobre dados oficiais. As resoluções que trataram do Programa Dinheiro Direto na Escola (PDDE) e PDDE-Escolas Sustentáveis, os próprios projetos político-pedagógicos das escolas pesquisadas, os textos extraídos da legislação pertinente ao tema e os sites institucionais constituíram o corpus de documentos, explorados para a complementação e enriquecimento dos dados. No aprofundamento, via processo de análise e interpretação, adotou-se elementos da Análise de Conteúdo como uma forma de decodificar as informações obtidas. Para realizá-la, diversificouse os procedimentos dando mais ênfase aos que se mostrassem mais apropriados dentro do material a ser analisado. Dentre eles, a "análise léxica, análise de categorias, análise da enunciação, análise de conotações” (CHIZZOTTI, 2006, p. 98), além da análise categorial e análise de enunciação. $\mathrm{Na}$ última, entendeu-se que além das palavras emitidas pelos participantes e seus 
significados, foi preciso desvelar também o sentido do que foi comunicado no momento do discurso, sobretudo, por se tratar de diferentes segmentos da comunidade escolar. Sabe-se que cada um deles percebe a realidade de um ponto de vista bastante particular, conforme o lugar que ocupa em seu espaço de vivência e trabalho.

$\mathrm{Na}$ organização e análise dos dados gerados, para se chegar às categorias e indicadores, foi utilizado o conjunto de procedimentos pertinentes à Análise de Conteúdo de Bardin (2011). Numa perspectiva mais ampla, entende-se que essa técnica de análise contribuiu ao propor um conjunto de procedimentos de categorização, cujo objetivo consistiu na busca tanto do entendimento da mensagem por meio da palavra verbalizada pelos participantes, como do sentido ou dos sentidos que pudessem emergir dessa palavra.

Grande parte dos autores refere-se à AC como uma técnica de análise da palavra, que possibilita, de forma prática e objetiva, elaborar inferências do que foi comunicado pelo participante. $\mathrm{O}$ texto transcrito é tratado como um meio dele se expressar e de o pesquisador, através de seu papel de analista, buscar categorias a partir das unidades de texto que se repetem. Assim, são descobertas expressões cada vez menores e mais abrangentes que as representem. Para tanto, realizou-se uma análise categorial caracterizada "por operações de desmembramento do texto em unidades, em categorias segundo reagrupamento analógicos” (BARDIN, 2011, p. 153).

As categorias foram construídas conforme os temas que emergiram do texto transcrito. Para classificar elementos das falas em categorias partiu-se da identificação do que elas tinham em comum, de modo que foi possível realizar tais agrupamentos. Foi realizada a pré-análise, uma fase de organização dos dados gerados e, na sequência, a leitura flutuante, a escolha de documentos que demarcassem o corpus de análise e a elaboração dos indicadores que orientaram a interpretação e a preparação formal do material (BARDIN, 2011).

A elaboração dos indicadores qualitativos constituiu o momento mais importante desses procedimentos, uma vez que eles sistematizaram o direcionamento para os resultados da pesquisa. Eles expressaram de modo mais tangível os resultados da boa articulação entre a gestão participativa, o fomento de projetos socioambientais pela União e o desenvolvimento sustentável nas escolas pesquisadas. Esses indicadores, definidos a partir das categorias encontradas, continham em si o 'significado' e o 'sentido' dos dados gerados. Eles permitiram alegar que a gestão participativa, no âmbito do financiamento de projetos escolares socioambientais, favorecia a concretização de projetos educacionais voltados para o desenvolvimento sustentável.

A fase de tratamento dos resultados deu-se mediante a inferência e interpretação de conceitos e proposições. Conforme Bardin (2011), esse é o momento em que flui a intuição do investigador na análise reflexiva e crítica das informações, para além do conteúdo explícito dos documentos, a partir da busca do conteúdo que está subentendido ou os sentidos e significados que se encontram ocultos nas entrelinhas e para além do imediatamente percebido e assimilado.

\section{A entrevista semiestruturada e o processo analítico-interpretativo dos dados}

A escolha dessa técnica de entrevista deu-se em função de proporcionar maior aproximação entre o pesquisador e a perspectiva dos entrevistados, bem como do entendimento e da captação dos aspectos "não visíveis" com relação aos dados (ROESCH, 1999, p. 159). 
$\mathrm{O}$ universo de pessoas entrevistadas limitou-se àquelas envolvidas diretamente na implementação do programa desenvolvido nas escolas do Município de Sobral. Assim, foi entrevistado um total de 15 participantes, todos pertencentes ao quadro da Secretaria de Educação. As quatro escolas definidas como o 'universo da investigação' serão identificadas como Escola A, Escola B, Escola C e Escola D, de modo a respeitar as exigências de anonimização, conforme o Termo de Consentimento Livre e Esclarecido assinado por todos os participantes.

Cada segmento - diretores, professores, alunos e coordenadores - foi identificado pelo respectivo nome do segmento e a letra da escola, acrescentados números conforme a quantidade do mesmo segmento em cada escola - por exemplo, "Aluno 1, Escola A"; Professor 2, Escola B"; "Coordenador, Escola C", e assim por diante. Todas as escolas mencionadas foram visitadas e seu funcionamento observado in loco. $\mathrm{O}$ maior percentual de participação atingido foi no segmento de alunos $(33,4 \%)$, seguido dos gestores $(26,6 \%)$, professores $(20 \%)$ e coordenadores $(20 \%)$.

Os dados gerados com os diferentes segmentos permitiram mapear informações relativas à gestão participativa e como ela implica na organização e na realização de projetos de desenvolvimento sustentável nas escolas contempladas. Também tornou possível levantar elementos para melhor compreender as formas de decisão a respeito da aplicação dos recursos financeiros, bem como identificar os atores da comunidade escolar que participaram mais diretamente desse processo. Verificou-se ainda alguns indicadores de eficiência a partir dos relatos - fornecidos pelos participantes - sobre os resultados alcançados pelos projetos desenvolvidos em suas respectivas escolas. No curso das visitas o pesquisador teve a oportunidade de verificar como cada escola lidou com o desafio de implementar, por meio da gestão participativa, projetos de desenvolvimento sustentável que promovessem a educação socioambiental.

Para averiguar a clareza das perguntas e a garantia de melhor qualidade do processo de geração de dados, realizou-se um estudo piloto sobre a entrevista semiestruturada, com um número de pessoas convidadas a participar reduzido do universo geral da entrevista. Em todas as entrevistas seguiu-se o mesmo roteiro de perguntas, com o objetivo de coletar as impressões de cada participante sem restringir a sua liberdade para expressar concepções, ideias e percepções relacionadas à temática abordada.

Para se alcançar maior nível de compreensão, fez-se necessário uma articulação entre as diferentes perspectivas de análise e de interpretação dos dados, por entender que não se tratam de ações isoladas entre si. Apenas por uma questão de organização didática, nominalmente, os dois processos aparecem em momentos distintos. À luz de Ribeiro (2016), a perspectiva analítico-interpretativa preserva o caráter de unidade, de intersecção e de interação entre a análise e a interpretação. Entende-se que é preciso estimular pesquisadores a romperem o vício da ordenação excessiva, muitas vezes induzidos pela preocupação de se fazer entender no "espaço analítico e imaginário da escrita" (PAUL, 2009, p. 302).

\section{Resultados e discussões: o caminho para as categorias}

A interpretação documental foi orientada para resultados com fins teóricos, com a expectativa de insights que emergiriam a partir dos dados e que pudessem ser incorporados ao corpus teórico da área de estudo ou do referencial de base investigado. A discriminação e 
agrupamento de unidades menores de análise ou unidades de registro (UR), etapa posterior à leitura flutuante, resultou nas categorias. Consistiu-se na organização de categorias amplas, agrupadas analogicamente a partir da segmentação do texto in verbatim de cada entrevista. Esse processo ocorreu por meio da identificação dos primeiros macroconceitos emergentes, sem preocupar-se com o critério tradicional de repetição de palavras, frases ou expressões. Os extratos do texto foram recortados conforme apresentassem uma assertiva completa relacionada ao objeto em estudo. Primeiramente foi concentrada em cada texto, e, no segundo momento, foram integradas e reunidas as repetições nos extratos de textos analisados e interpretados em conjunto.

Para tanto, emergiram três categorias: Concepção de gestão participativa, Real capacidade de atuação, e Conceitos emergentes de sustentabilidade escolar. Essas três categorias foram tratadas como a 'porta de entrada' do processo de categorização, ou seja, representaram os grandes eixos de direcionamento para as demais etapas de redução. Denominou-se a terceira categoria de 'conceitos emergentes', uma vez que não se tratavam de definições formais ou embasadas teoricamente, mas sim da concepção de cada um, elaborada tão-somente pela própria intuição, guiadas pelo senso comum daqueles participantes. Apesar de emergirem do que se sobressaiu como convergência entre os recortes de maior ênfase no material gerado pelas entrevistas com os participantes, foi mantida a conexão entre as três categorias e os três objetivos específicos da tese em questão.

O primeiro, por destacar a atuação da gestão participativa com relação ao desenvolvimento de projetos sustentáveis, suscitou a categoria "concepção de gestão participativa". Observou-se de comum no material gerado, que todas as vezes que os participantes eram questionados acerca dessa questão, eles referiam-se às suas percepções sobre o que passaram a conceber como gestão participativa pelo modo como as mudanças começaram a ocorrer a partir desses projetos.

O segundo tratou da aplicação dos recursos recebidos via PDDE em escolas que adotam a gestão participativa, o que resultou na categoria "real capacidade de atuação". Nesse caso, a ideia foi investigar qual a efetividade da atuação gestão ao obter tais condições, ou seja, ao ser contemplada com os recursos do PDDE-Escolas Sustentáveis.

Por fim, no terceiro objetivo, entendeu-se que para identificar os indicadores qualitativos que sinalizassem a contribuição da gestão participativa seria preciso direcionar a 'escuta' para a concretização dos projetos socioambientais. Nesse momento, os participantes foram convergentes em verbalizar sua compreensão acerca do conceito de 'sustentabilidade escolar'. $\mathrm{Na}$ elaboração dessa concepção tácita ou ao expressar sua percepção do que entendiam por 'sustentabilidade escolar', cada um pontuou os benefícios dessa interação bem-sucedida na escola. Esse modo de expressar o pensamento, com a articulação espontânea dos dois temas - gestão participativa e incremento de projetos voltados para a educação socioambiental -, foi o que concentrou toda a riqueza de detalhes para acessar o caminho de resposta ao problema de pesquisa.

Prosseguiu-se na categorização com a composição de núcleos de sentido, com a intensificação do processo de redução. Com uso do 'paradoxo', buscou-se categorizar em 'pequenas unidades, cada vez mais abrangentes', na busca de visualizar os indicadores de gestão bem-sucedida dos recursos da União em prol da sustentabilidade ambiental na escola. O modo de traduzir e expressar os núcleos de sentido foi por meio de palavras-polo (BARDIN, 2011), 
Gestão participativa e sustentabilidade socioambiental: ...

às quais foram transformadas em indicadores denominados indicadores de sustentabilidade socioambiental em escolas de gestão participativa, como resultado final do processo de categorização.

Na última etapa, elaborou-se a (re)constituição do objeto, entendida como uma nova leitura da sustentabilidade socioambiental na escola, dessa vez, baseada em uma perspectiva diferente: a perspectiva que emergiu da união entre as teorias constituídas e a visão daqueles participantes. O prefixo "re" significa que um objeto, já existente na ciência da gestão escolar, foi novamente constituído a partir de um novo referencial. Agora, esse referencial foi fundamentado na realidade empírica das quatro escolas que efetivamente realizaram projetos de sustentabilidade socioambiental. O modo de expressar o resultado dessa etapa do processo de categorização foi por meio da elaboração de uma resposta à questão que motivou o estudo. Essa resposta foi considerada a aproximação da teoria com a fundamentação dos dados, uma vez que explica a relação entre gestão participativa e desenvolvimento sustentável no contexto do financiamento público de projetos escolares. Não se pode perder de vista, contudo, que essa teorização da realidade da pesquisa foi fundamentada nos dados gerados naquela realidade, por intermédio da investigação realizada.

\section{Dados classificados como categorias}

Os dados para as categorias foram gerados pela extração de expressões das entrevistas. Na composição de núcleos de sentido em palavras-polo, a redução se intensificou. $\mathrm{O}$ caminho para encontrá-las consistiu em reduzir as categorias a palavras ou expressões menores e de modo menos descritivo. Caracterizou-se como um procedimento de 'transição', visto que, apesar de evoluir da descrição in verbatim para um processo de abstração, ainda se misturavam termos usados pelos participantes e termos não literais, conforme a interpretação atribuída pelo pesquisador. As expressões significativas foram agrupadas por segmento e categoria para integrar as respostas dos participantes das quatro escolas, o que possibilitou a formação dos núcleos de sentido (BARDIN, 2011). (Quadro 1).

Quadro 1. Composição das palavras-polo por segmento e categoria

\begin{tabular}{|c|c|c|c|}
\hline \multirow[b]{2}{*}{ SEGMENTO } & \multicolumn{3}{|c|}{ PALAVRAS-POLO } \\
\hline & $\begin{array}{c}\text { Concepção de Gestão } \\
\text { Participativa }\end{array}$ & $\begin{array}{c}\text { Real Capacidade de } \\
\text { Atuação }\end{array}$ & $\begin{array}{l}\text { Conceitos emergentes de } \\
\text { Sustentabilidade Escolar }\end{array}$ \\
\hline Alunos & Misturar todo mundo & Viagens e passeatas & $\begin{array}{l}\text { Só pra mim não vai servir de } \\
\text { nada }\end{array}$ \\
\hline Professores & Todo mundo influencia & $\begin{array}{l}\text { Aula no aterro } \\
\text { sanitário }\end{array}$ & $\begin{array}{l}\text { Educação melhor, cidadãos } \\
\text { melhores }\end{array}$ \\
\hline Coordenadores & Todos são ouvidos & $\begin{array}{l}\text { Participação em feiras } \\
\text { regionais }\end{array}$ & $\begin{array}{l}\text { Mudança na comunidade } \\
\text { como um todo }\end{array}$ \\
\hline Diretores & Todos têm a palavra & $\begin{array}{l}\text { Oficinas com a } \\
\text { autarquia municipal }\end{array}$ & Sentimento de pertencimento \\
\hline
\end{tabular}

Fonte: Elaborado pelos autores. 


\section{Categoria 1 - Concepção de Gestão Participativa}

Conforme se observa no Quadro 1, optou-se pelo núcleo de sentido "todo mundo" como um eixo que trouxe conexão aos quatro segmentos. Compreendeu-se que o núcleo de sentido que emergiu foi algo que remeteu à ideia de totalidade, de reunião e de união plena que, se não traduzir aquela realidade na mesma intensidade, pelo menos está estabelecida como um desejo coletivo latente. Esse desejo, se identificado, reconhecido e expressamente verbalizado pelo e entre o grupo, pode se transmutar em uma meta e, gradativamente, tornar-se um desafio conjunto que "todo mundo", naquelas escolas, buscará superar com igual empenho. Interessante notar que, nas respostas dos participantes que geraram a Categoria 1 , cada segmento acrescentou o seu "parceiro natural", ou seja, aquela parte que parece estar mais diretamente relacionada ao seu espaço de convívio. Em outras palavras, o aluno mencionou a família ou os pais, o professor e o coordenador mencionaram a comunidade e o diretor mencionou as parcerias.

\section{Categoria 2: Real capacidade de atuação}

O eixo de conexão entre os quatro segmentos emergiu como a ideia de explorar e atuar em espaços externos à escola. Conforme as palavras da Categoria 2, abstraiu-se como verbalização comum a todos eles as atividades que cada segmento realizou em contato com o meio, o que suscita uma preocupação ou, pelo menos, preferência pela proximidade com o ambiente mais amplo. Instiga a deduzir que o sentido atribuído à real atuação nesse possível caminho para uma mudança de mentalidade está nas relações que estabelecemos com o meio, no convívio em comunidade, e na interação do aprendizado que transcenda os muros da escola para beneficiar o outro de forma mais abrangente. Inferiu-se assim que a visão de cada segmento sobre a real capacidade de atuação evoluiu no sentido de aproximar-se do conceito de sustentabilidade ambiental, ou seja, é possível perceber uma correlação entre teoria e prática.

Nos relatos das entrevistas foi observada a preocupação em melhorar o espaço em que todos convivem e em instigar a participação da comunidade. Isso tornou-se perceptível pelo foco do estudo, direcionado a compreender a sustentabilidade como aquelas ações voltadas para o suprimento das próprias necessidades, porém sem comprometer o futuro das próximas gerações. Observou-se que houve movimentos no sentido de explorar os espaços e desenvolver o cuidado com o meio ambiente, além da expressão das ideias de "olhar para o futuro" e de inclusão do outro, mesmo que não estivessem presentes de forma consciente ou explícita.

\section{Categoria 3: Conceitos Emergentes de Sustentabilidade Escolar}

$\mathrm{O}$ que emergiu nessa categoria foi a visão de conjunto, de forma que que a mesma corrobora com as duas anteriores. A fala dos quatro segmentos, de acordo com o núcleo de sentido que suscitou, convergiu no sentido de transcender as próprias necessidades e de olhar para além de si. Verificou-se que houve um movimento na direção do outro e do espaço, uma predisposição em estender um benefício ou aquilo que faz bem para si, de incluir o outro e o entorno como beneficiários das boas ações. Outras palavras variantes, cujo sentido não rompe o vínculo com a ideia comum foram mencionadas, entre elas: convivência, preservação, mudança, uso racional. E a palavra-mestre que apareceu nas falas dos segmentos foi "meio-ambiente".

O processo de redução, que se iniciou, de forma mais intensa, a partir destas palavras -polo, foi desenvolvido até a saturação, limite estabelecido não somente pela repetição, mas pela proporção com que o sentido atribuído à categoria contemplasse a ideia que se queria 
condensar e transmitir. Os indicadores a serem apresentados a seguir representaram a síntese das categorias supracitadas.

\section{Os indicadores de sustentabilidade socioambiental em escolas de gestão participativa}

Cada indicador reúne, em seu significado, elementos que respondem à questão que motivou a pesquisa realizada. Esses elementos tanto guardam uma estreita relação com o campo da sustentabilidade ambiental no contexto escolar como atribuem sentido e significado à interação desse campo com a gestão participativa. A Figura 1 ilustra de que modo eles se interconectam e agem naquele ambiente

Figura 1. Holograma Gestão participativa para a sustentabilidade socioambiental na escola

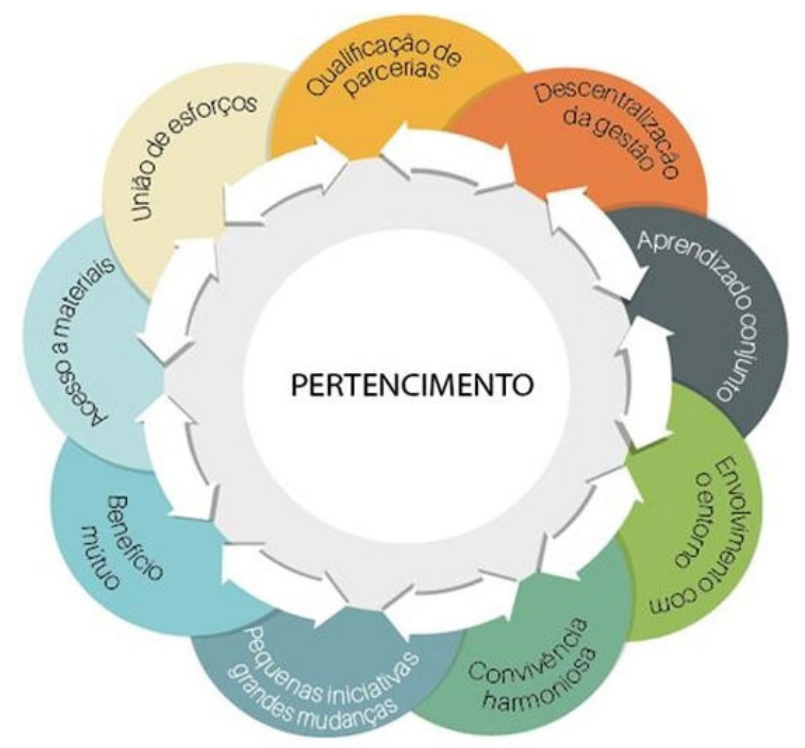

Fonte: elaborado pelos autores.

\section{Pertencimento: o indicador catalisador}

O sentimento de pertencimento pode ser concebido como uma 'ausente-presença' na sociedade atual. Sinaliza um perfil de sociedade marcada pela exclusão, pelo distanciamento cada vez mais intenso entre as pessoas. Esse distanciamento pode se estender também a um distanciamento de si, o que remete à busca de identidade diante do sentimento de que há um vazio no que deveria existir de comum e de aglutinador. Trata-se de uma demanda que integra sustentabilidade escolar e gestão participativa, na medida em que os atores que dinamizam essa 
realidade evocaram o sentimento de pertencimento como algo que preenche o espaço vago do comum-aglutinador. À luz de Sousa (2010, p. 34), o sentimento de pertencimento, “[...] se traduz de forma visível, em sentidos e motivações diversos dos de suas raízes, sustentando a busca de participação em grupos, tribos e comunidades que possibilitem enraizamento e gerem identidade e referência social, ainda que em territórios diferentes [...]”.

A ideia de pertencimento abrange e impulsiona energia e sustenta os demais indicadores, uma vez que se trata de um benefício que parte de dentro de 'si' para o outro e o ambiente. Conecta-se com os demais indicadores e foi entendido como um elemento gerador e articulador de uma escola com gestão participativa que promove o desenvolvimento sustentável.

A categoria em questão foi apreendida como um indicador catalisador por sinalizar o potencial de articular a sustentabilidade e a gestão participativa em pleno processo de interação. Segundo Sousa (2010, p. 34), a busca pelo pertencimento no sentido de encontrar o comum -articulador, por si suscita a "quebra tradicional de fronteiras entre o local e o global, o público e o privado, o comum e o individual e a comunidade e a sociedade, gerando tanto hibridismos quanto novas formas de tensão e de conflito". Ainda instiga a participação pela valorização do coletivo através de conexões afetivas e vínculos históricos estabelecidos com a comunidade.

\section{União de esforços: uma consequência do olhar para além de si}

Esse indicador expressou a capacidade daquela comunidade escolar de olhar para além de si e enxergar que há pessoas à sua volta, ou seja, enxergar o meio e o ambiente em que mais de um convive. Para enxergar o outro é preciso enxergar a si, sentir-se pertencido em uma comunidade, desenvolver a confiança para acreditar que da união é possível realizar o que parecia um obstáculo intransponível.

Qualificação de parcerias: uma exigência para o sucesso dos projetos escolares

Da união de esforços resulta a qualificação de parceria. Esse indicador requer e remete à articulação intensa na busca de melhores resultados para os projetos escolares criados. Articulação sem gestão participativa inexiste. E, muitas vezes, e conforme aspectos que surgiram em diferentes relatos dos participantes, nem a gestão participativa lograria êxito sem as parcerias. A realidade brasileira está aí para comprovar essa inferência, até mesmo com base na afirmação de que os recursos/financiamentos disponibilizados, quando existem, não são suficientemente plenos para gerar resultados sustentáveis. A qualificação de parcerias resgata a ideia de rompimento de fronteiras presente no indicador pertencimento, bem como a aceitação da ideia de hibridismo, ou seja, de mistura, de interpenetração de diferentes processos para se alcançar o objetivo comum.

\section{Descentralização da gestão: abertura para a sustentabilidade}

Buscar parcerias demanda e implica na descentralização da gestão. Portanto, o tema gestão participativa no âmbito da sustentabilidade ambiental escolar é de suma importância, uma questão decisiva para que mudanças ocorram. Mas o conceito de descentralização tem o peso de sua significação, intensificada e materializada na proporção em que os segmentos incorporam o conceito de comunidade, especialmente no que tange à gestão escolar participativa e de ações 
Gestão participativa e sustentabilidade socioambiental: ...

sustentáveis. Descentralizar consiste antes de tudo em abertura e flexibilização. Trata-se de um movimento na direção do outro para acolher suas ideias e propostas, geralmente diferentes daquele que lidera. Em regra, aqueles que ocupam posições na base são os que enxergam as lacunas, exatamente por sofrerem o impacto das ações - competentes ou incompetentes - do gestor.

\title{
Aprendizado conjunto
}

Nomeou-se aprendizado conjunto o que se reporta como resultado dos anteriores, na medida em que o pertencimento levou à união de esforços e à busca de parcerias como consequência da descentralização. Pode ser denominado como uma consequência natural da gestão participativa que gera ações de sustentabilidade socioambiental escolar, visto que a integração das pessoas de uma comunidade e o aprendizado com o outro promovem resultados consistentes, com características de tornarem-se sustentáveis.

\section{Envolvimento com o entorno}

Elemento visivelmente presente nas quatro escolas refletiu-se como uma preocupação coletiva com o outro, partilhada por todos. Em uma resposta do diretor da Escola C, ficou claro não só a existência do aprendizado em conjunto, mas também a mobilização na direção de interagir com o entorno, uma predisposição para a convivência produtiva e afetiva. Em decorrência disto, nota-se os resultados frutuosos para o ambiente da escola e da comunidade.

\begin{abstract}
Nós chamamos o representante da comunidade, líderes comunitários, associação, e a partir dai nós desencadeamos uma série de ações. E aí a primeira ação que nós pensamos de caráter coletivo foi uma mobilizaşão na comunidade, identificando ali os focos onde tinha a incidência, por exemplo, de lixo. [Diretor - Escola C].
\end{abstract}

\section{Convivência harmoniosa: fator de proximidade}

A percepção de harmonia emergiu, numa ordem natural de posterioridade, da ideia de envolvimento com o entorno. Conviver pressupõe 'viver com' e em harmonia. Ninguém se envolve deliberadamente com o que suscita conflito, desarmonia. A tendência primeira é de se afastar, se isolar daquilo que faz mal em vez de bem. Distanciamento e isolamento não foram elementos presentes naquelas quatro comunidades. Apesar das imperfeições de qualquer relação dessa amplitude - escola e comunidade -, a harmonia pareceu ser algo bastante presente. As palavras de Tajfel (1982) ilustram bem essa questão, quando o autor argumenta que as pessoas constroem e são construídas de modo simbiótico pelo seu entorno. Higuchi (2002) o corrobora quando concorda que a constituição da pessoa se dá, na maior parte das vezes, em uma dinâmica relacional complexa com o entorno onde convive com as outras pessoas.

Pequenas iniciativas-grandes mudanças, benefício mútuo e acesso a materiais

Os três últimos indicadores - pequenas iniciativas-grandes mudanças, benefício mútuo e acesso a materiais dispensam uma definição mais detalhada, uma vez que parecem refletir uma dimensão material e de forma mais explícita. Esses três indicadores suscitaram uma ideia de decorrência, de consequência, de implicações a partir da ação dos sete primeiros. 


\section{Considerações finais}

Pontuar aspectos e apresentar elementos que indiquem os impactos do financiamento de projetos de sustentabilidade socioambiental nas quatro escolas pesquisadas, através dos conceitos de desenvolvimento sustentável aplicados ao contexto escolar, constituiu uma importante contribuição do estudo realizado. Conforme o consenso, embasado na flagrante realidade educacional que o país vive, atualmente, é mister considerar a dificuldade de recursos como um fator de grande obstáculo para a melhoria da qualidade do ensino em si, ou seja, a escola sendo capaz de cumprir o seu papel acadêmico. Estender esse esforço ao desenvolvimento de projetos que extrapolem as paredes da sala de aula para enxergar o ambiente parece, a olhos nus, uma exigência hercúlea diante das dificuldades enfrentadas pelos gestores, equipes de professores e até os próprios alunos.

É preciso um fator exógeno de alguma proporção mais elevada para que esforços sejam estimulados nesse sentido, até mesmo para que a escola possa vivenciar os benefícios disso para o próprio processo de aprendizagem dos alunos. O fator que se deu evidência para realizar esse estudo foi o financeiro. Entendeu-se que a ausência do recurso material mínimo pode levar a escola à estagnação, causada pela sensação de impotência diante dos problemas econômicos que parecem, a priori, sem solução. Sendo assim, buscou-se mostrar o lado de quem tem essa necessidade aparentemente suprida e o modo como reage ao cumprimento de sua responsabilidade com as questões socioambientais.

O caminho que se buscou para investigar essa problemática foi a formulação de indicadores de que esse financiamento dos projetos exerceu impacto. Contudo, não houve a preocupação, pela própria natureza da pesquisa, de se estabelecer indicadores quantitativos. Tratou-se de uma pesquisa essencialmente qualitativa, sendo todos os instrumentos de geração de dados voltados para tal abordagem. Os indicadores foram gerados a partir de um processo de categorização que levou em conta o discurso dos participantes, as suas percepções acerca das mudanças vivenciadas na escola no período combinado por ocasião da entrevista. Não houve a preocupação em objetivar quantitativamente a subjetividade dessas percepções, por entender que elas expressaram o ponto de vista de cada participante; que todos eles são atuantes e vivenciam aquela realidade, tendo assim propriedade para verbalizar os impactos exercidos pelos projetos; que houve e foram valorizadas as convergências que emergiram desses discursos. Sendo assim, com base na exploração teórica da revisão bibliográfica e na exploração dos elementos que emergiram da dimensão prática da pesquisa realizada em campo, foram gerados os indicadores de sustentabilidade socioambiental em escolas de gestão participativa, exercício avaliativo que se mostrou eficaz para a percepção coletiva dos projetos implantados nas escolas estudadas. Percebe-se que é possível utilizar a metodologia proposta para avaliar outros projetos, a resposta e a aceitabilidade da comunidade escolar, bem como modelos alternativos de gestão das escolas.

Explorar o campo conceitual que circunda as questões de sustentabilidade socioambiental pareceu desenvolver um processo gradual de conscientização no sentido do olhar que se volta para fora de si. O próprio entendimento de que ações sustentáveis apontam, em sua essência, na direção das gerações futuras, já se constituiu um 'sair de si' e olhar em volta. Como foi explicitado na definição dos indicadores, foi construída uma concepção nova de convivência entre os envolvidos. Trata-se de uma convivência que "se importa", ou seja, uma compreensão 
de que aquele que está ao meu redor é parte intrínseca de mim, desde que faça parte do meu espaço de convivência, mesmo que isso não implique proximidade física ou geográfica. Existe um brilho diferente quando a vida abarca a presença do outro e a sensação de realidade construída por todos reforça a certeza de que não estão sozinhos ou isolados no mundo, mas que a responsabilidade e o comprometimento com as outras pessoas e com o ambiente garantem a segurança de todos, mas também de cada um. Entende-se que as comunidades escolares estudadas experimentaram ricas vivências, que poderiam ser mais frequentes para a construção de uma solidariedade forte e duradoura entre os membros da escola e das famílias.

Formou-se uma espécie de rede de cooperação, cujo tecido foi composto pelos membros da escola, pelos membros da comunidade e pelos parceiros que se habilitaram a prestar serviços. Também pelo próprio governo que proporcionou políticas públicas ao Município de Sobral e disponibilizou recursos para que esses projetos fossem executados.

Para que a promoção da sustentabilidade socioambiental seja eficaz, a escola deve ater-se às necessidades de sua comunidade, além de elaborar projetos que tragam benefícios extramuros, como mencionado nos relatos aqui apresentados. A nova tendência social nos impulsiona para uma realidade onde os muros da escola não satisfazem mais a necessidade premente de nossos alunos. A escola precisa se renovar, adaptar e repaginar. A educação ambiental deve ser trabalhada no currículo escolar de maneira mais efetiva, com o estímulo ao seu tratamento de modo transdisciplinar e enquanto preocupação necessária e primordial.

\section{Referências}

BARDIN, L. Análise de conteúdo. São Paulo: Edições 70, 2011.

BERALDO, F.; PELOZO, R. C. B. A gestão participativa na escola: tendências e perspectivas. Revista Científica Eletrônica de Pedagogia, Garça, v. 5, n. 10, p. 1-23, 2007. Disponível em: <http://faef.revista.inf.br/imagens_arquivos/arquivos_destaque/ SU3onzBiYiLUhza_2013-6-28-15-24-32.pdf>. Acesso em: 8 jul. 2013.

BRASIL. Ministério da Educação. Resolução no 18 de 21 de maio de 2013. Dispõe sobre a destinação de recursos financeiros, nos moldes operacionais e regulamentares do Programa Dinheiro Direto na Escola (PDDE), a escolas públicas municipais, estaduais e distritais que possuam alunos matriculados na educação básica, de acordo com dados extraídos do Censo Escolar do ano imediatamente anterior ao do repasse, a fim de favorecer a melhoria da qualidade de ensino e a promoção da sustentabilidade socioambiental nas unidades escolares. Brasília, 2013. Disponível em: <https://tinyurl.com/yau4rc97>. Acesso em: 2 maio 2018.

BRITO, R. O. Gestão e comunidade escolar: ferramentas para a construção de uma escola diferente do comum. Brasília: Liber Livro, 2013.

BRITO, R. O. Gestão participativa e sustentabilidade socioambiental: um estudo em escolas da rede pública de SOBRAL-CE. 2016. 192 f. Tese (Doutorado em Educação) Universidade Católica de Brasília, Brasília, 2016.

CHIZZOTTI, A. Pesquisa em ciências humanas e sociais. 8. ed. São Paulo: Cortez, 2006. 
Brito, R. O.; Cunha, C.; Siveres, L.

ESCOLANO BENITO, A.; HERRERO SUÁREZ, H.; BRYAN, N. A. P. Educação e conhecimento: para um futuro sustentável. São Paulo: Alínea, 2011.

HIGUCHI, M. I. G. Psicologia ambiental: uma introdução às definições, histórico e campos de estudo e pesquisa. Canoas: ULBRA, 2002.

LAKATOS, E. M.; MARCONI, M. A. Técnicas de pesquisa. 5. ed. São Paulo: Atlas, 2002.

LOUREIRO, C. F. B.; AZAZIEL, M.; FRANCA, N. (Org.). Educação

ambiental e gestão participativa em unidades de conservação. Rio de Janeiro:

Ibase, 2003. Disponível em: <http://www.ibama.gov.br/sophia/cnia/livros/

educacaoambientalegestaoparticipativaemunidadesdeconservacao.pdf $>$. Acesso em: 20 fev.

2016.

LÜDKE, M.; ANDRÉ, M. E. D. A. Métodos de coleta de dados: observação, entrevista e análise documental. In: LÜDKE, M.; ANDRÉ, M. E. D. A. Pesquisa em educação: abordagens qualitativas. 2. ed. São Paulo: EPU, 2003. p. 25-44.

PAUL, P. Formação do sujeito e transdisciplinaridade: história de vida profissional e imaginal. São Paulo: Trion, 2009.

RIBEIRO, O. C. Criatividade na expertise: implicações para processos de aprendizagem de alto nível. 2016. 389 f. Tese (Doutorado em Educação) - Universidade Católica de Brasília, Brasília, 2016.

ROESCH, S. M. A. Projetos de estágio e de pesquisa em administração: guias para estágios, trabalhos de conclusão, dissertações e estudos de casos. São Paulo: Atlas, 1999.

SOUSA, M. W. O pertencimento ao comum mediático: a identidade em tempos de transição. Significação: revista de cultura audiovisual, São Paulo, v. 37, n. 34, p. 31-52, 2010.

TAJFEL, H. Grupos humanos e categorias sociais. Lisboa: Horizonte, 1982.

TURATO, E. R.; RICAS, J.; FONTANELLA, B. J. B. Amostragem por saturação em pesquisas qualitativas em saúde: contribuições teóricas. Cadernos de Saúde Pública, Rio de Janeiro, v. 24, n. 1, p. 17-27, jan. 2008. Disponível em: < https://doi.org/10.1590/S0102311X2008000100003>. Acesso em: 9 out. 2015.

VELASCO, S. L. Notas sobre ecomunitarismo e esporte educativo e cooperativo.

Diaphonía, Toledo, v. 1, n. 1, p. 155-168, 2015.

VELlOSO, J. P. R. et al. A questão ambiental e a Rio +20: economia verde como oportunidade global para o Brasil. Rio de Janeiro: Elsevier, 2012.

Artigo recebido em 28/03/2017. Aceito em 25/10/2017.

Contato: SQSW 103, Bloco E, ap. 305, Setor sudoeste, Brasília, DF, CEP 70670-305, Brasil. 